\title{
Spreadability Testing of Powder for Additive Manufacturing
}

\author{
Christopher Neil Hulme-Smith', Vignesh Hari', and Pelle Mellin² \\ 'Department of Materials Science and Engineering, KTH Royal Institute of Technology, Stockholm, Sweden \\ ${ }^{2}$ Swerim AB, Kista, Stockholm, Sweden
}

Received November 30, 2020; accepted December 4, 2020; published online January 14, 2021

\begin{abstract}
The spreading of powders into thin layers is a critical step in powder bed additive manufacturing, but there is no accepted technique to test it. There is not even a metric that can be used to describe spreading behaviour. A robust, image-based measurement procedure has been developed and can be implemented at modest cost and with minimal training. The analysis is automated to derive quantitative information about the characteristics of the spread layer. The technique has been demonstrated for three powders to quantify their spreading behaviour as a function of layer thickness and spreading speed.
\end{abstract}

Keywords: Spreadability, Powder metallurgy, Additive manufacturing, Image analysis

\section{Verbreitbarkeitsprüfung von Pulver zur additiven Herstellung}

Zusammenfassung: Das Aufbringen von Pulvern in dünne Schichten ist ein kritischer Schritt bei der Herstellung von Pulverbettadditiven, es gibt jedoch keine akzeptierte Technik, um dies zu testen. Es gibt nicht einmal eine Metrik, mit der das Ausbreitungsverhalten beschrieben werden kann. Es wurde ein robustes, bildbasiertes Messverfahren entwickelt, das mit geringen Kosten und minimalem Schulungsaufwand implementiert werden kann. Die Analyse wird automatisiert, um quantitative Informationen über die Eigenschaften der Ausbreitungsschicht abzuleiten. Die Technik hat gezeigt, dass drei Pulver ihr Ausbreitungsverhalten als Funktion der Schichtdicke und der Ausbreitungsgeschwindigkeit quantifizieren können.

Schlüsselwörter: Verteilbarkeit, Pulvermetallurgie, Additive Fertigung, Bildanalyse

\footnotetext{
$\overline{\text { C. N. Hulme-Smith, MA (Cantab) MSci PhD ( } \bowtie) ~}$ Department of Materials Science and Engineering, KTH Royal Institute of Technology, Brinellvägen 23,

10044 Stockholm, Sweden

chrihs@kth.se
}

\section{Introduction}

In powder bed additive manufacturing, the formation of thin layers is critical. The powder is melted in a selected pattern to build a component. If the spread layer is not of a consistent thickness or density, the build quality will be poor [1].

There are many established techniques to quantify flowability. Each has one or more metrics associated with it and some are standardised [2-6]. There are no established techniques or metrics to measure the spreading of powders (spreadability). The word "spread" does not even appear in the standardized terminology for additive manufacturing $[7,8]$. Flowability is sometimes used to infer spreadability, but flowability "is not necessarily correlated to" spreadability [9].

Very simple, inexpensive equipment operated manually can give quantitative spreadability information [10]. However, in manual testing, the investigator can influence the results. Conversely, a custom-built spreading machine has been used to analyse powder via image analysis, video analysis, and laser profilometry [11, 12]. Other specialist machines are under development that can be retrofitted onto additive manufacturing systems [13]. One system uses a custom-built automated spreader to spread thin layers on a balance. This then allows the density of powder to be found [14].

In the current study, an automated measurement technique is proposed. Image analysis provides several metrics that can be combined to understand spreading behaviour. Further developments could also provide additional massbased measurements to give information about packing within the layer.

\section{Materials and Methods}

Automated testing machines ("thin film applicators") are already used in the paint and food industries. One such machine is the TQC Sheen AB4120 (Fig. 1). This machine has a maximum spread area of $43 \mathrm{~cm} \times 30 \mathrm{~cm}$, which is representative of many metal 3D-printers. The range of veloc- 


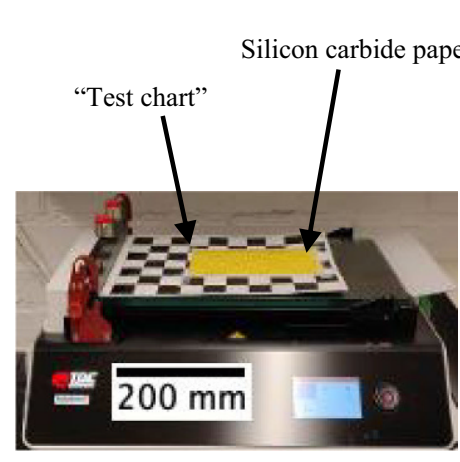

a

Fig. 1: TQC Sheen AB4120 film applicator with a additional silicon carbide paper; b doctor blade with adjustable height, as used in the current study

ities of the spreader, known as the recoater speed, is between 0.1 and $500.0 \mathrm{~mm} \mathrm{~s}^{-1}$ to an accuracy of $1 \%$. In early trials, silicon carbide paper was used to provide a rough surface for powder spreading and provide good colour contrast (Fig. 1a).

A doctor blade of adjustable height was used, which reduced the width of the test area to $25 \mathrm{~cm}$ (Fig. 1b). Tests were performed on a machined tool-steel plate, which is similar a metal 3D printer's build plate (Fig. 2).

A tripod-mounted Canon 700D camera $(18-55 \mathrm{~mm}$ lend, automatic mode) was pointed vertically at the geometric centre of the test plate and kept fixed throughout all experiments. The optimum position for lighting was either side at the height of the test area (Fig. 2). This illuminates the plate without forming reflexions in the camera.

Each image file was analysed using the image analysis program ImageJ [15]. A macro was written to automate the analysis:

1. Crop the image.

2. Split the image into three colour channels (red, green, blue)

3. Calculate the difference between the red and blue intensity of each pixel. The result is different for the powder and the steel plate.

4. Apply an automated threshold to classify pixels as powder or steel plate.

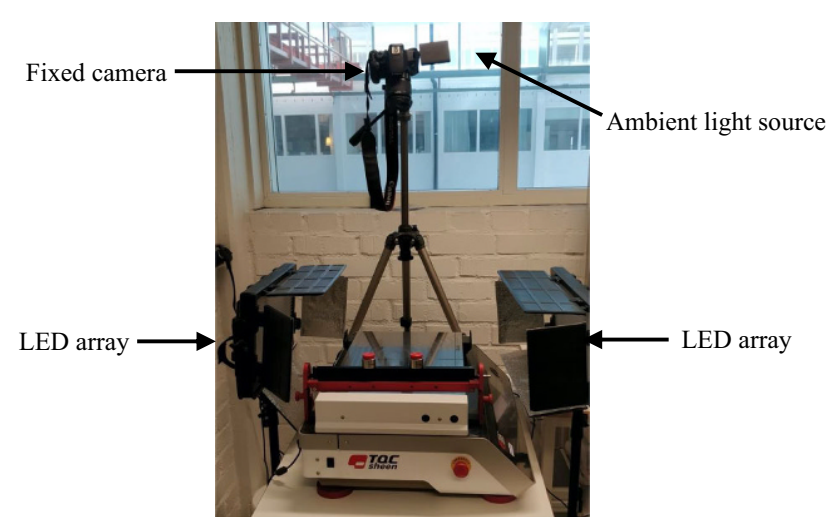

Fig. 2: Camera and lighting setup for experiments in the current study. The LED arrays were turned on at full intensity with a light temperature of $5000 \mathrm{~K}$; room lights were turned off but there were ambient light sources

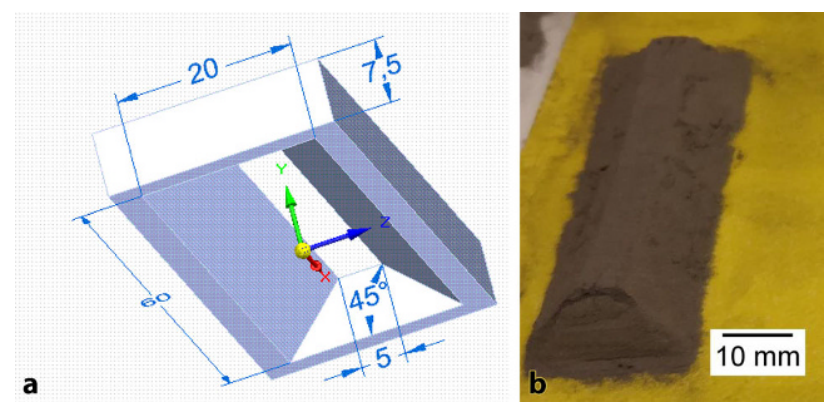

Fig. 3: a Custom-designed powder dispenser and $\mathbf{b}$ a powder sample dispensed using the funnel. Powder is poured through the top slot of the dispenser and after filling, the funnel dispenser is lifted off the sample

5. Measure the total area covered by powder.

6. Draw a convex hull (Fig. 3) around the powder and measure its area.

7. Draw a rectangular bounding box with one edge parallel to the direction of spreading (Fig. 3) around the powder and measure its area.

8. Divide the area measured in Step 5 by that found in Step 6 and, separately, Step 7.

Three powders were subjected to spreading and analysis using the procedure outlined above (Table 1). The recoater speed was varied between 50 and $200 \mathrm{~mm} \mathrm{~s}^{-1}$. The nominal layer height was 50,70 or $100 \mu \mathrm{m}$. Powder was prepared for testing using a custom dispenser, produced using fused deposition modelling (Fig. 4).

Flowability metrics (Hall and Carney flow time and a stability and variable flow rate test in a Freeman FT4 powder rheometer) were also recorded.

\begin{tabular}{|lll|}
\hline $\begin{array}{l}\text { TABLE } 1 \\
\text { Powders tested. }\end{array}$ & $d$ is the particle diameter \\
\hline Designation & Composition & Size fraction \\
\hline A & 1 & $20 \leq d / \mu \mathrm{m} \leq 53$ \\
\hline B & 1 & $d \leq 22 \mu \mathrm{m}$ \\
\hline C & 2 & $20 \leq d / \mu \mathrm{m} \leq 53$ \\
\hline
\end{tabular}

Fig. 4: Example of powder outline (blue), convex hull (yellow) and bounding box (pink) 

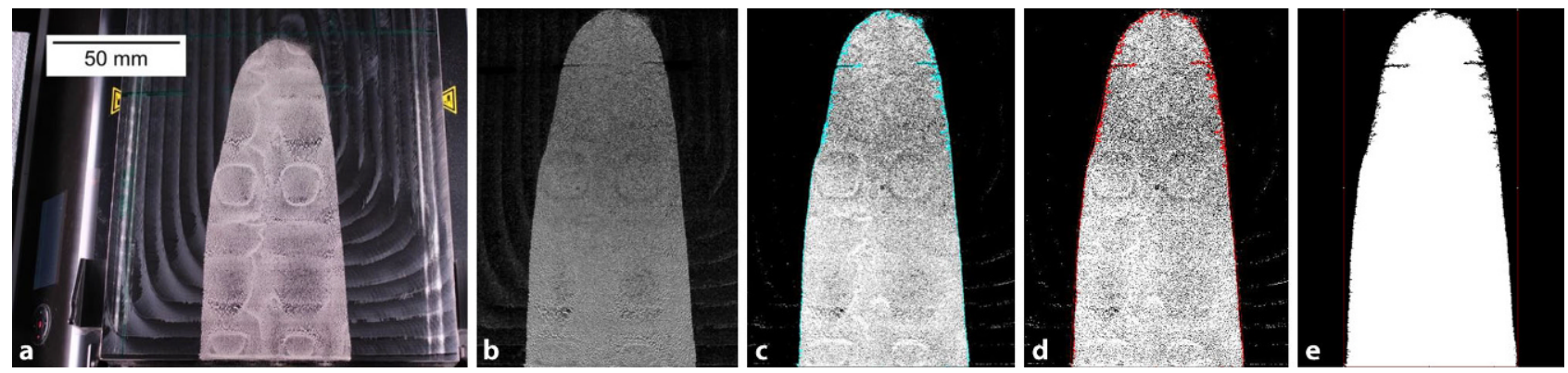

Fig. 5: Example of image analysis: a photograph of spread layer; $\mathbf{b}$ result of subtracting the green colour channel from the red; $\mathbf{c}$ automatically identified outline of the powder; d outline overlaid with automatic convex hull; e automatic bounding box

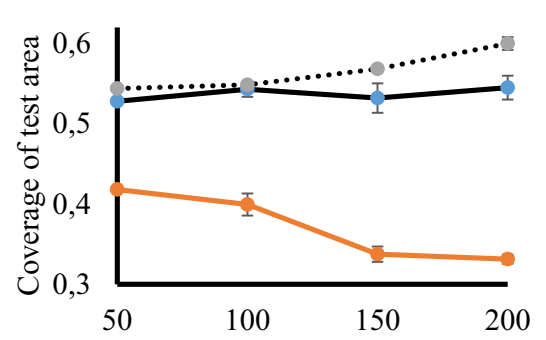

a

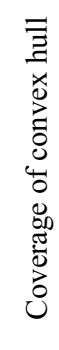

b

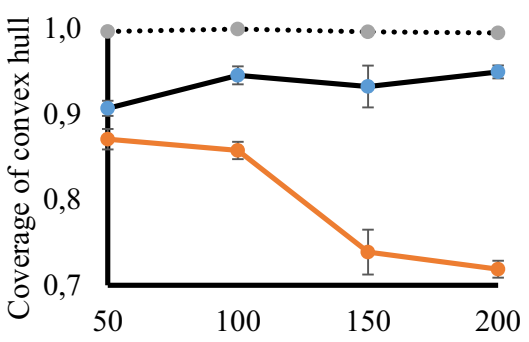

Recoater speed / $\mathrm{mm} \mathrm{s}^{-1}$

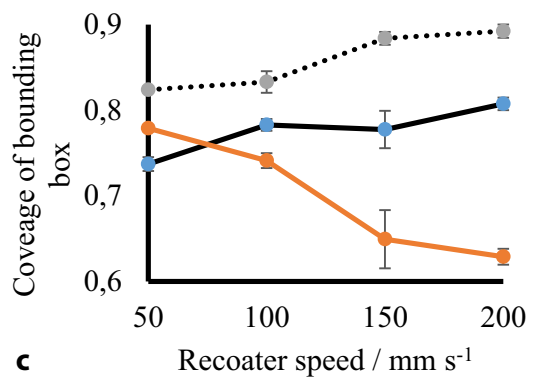

C $\quad$ Recoater speed $/ \mathrm{mm} \mathrm{s}^{-1}$

Fig. 6: Coverage of powders indicated during spreadability tests for $50 \mu \mathrm{m}$ thick layers

\begin{tabular}{|c|c|c|c|c|c|}
\hline Powder & $\begin{array}{l}\text { Hall flow } \\
\text { time/s }\end{array}$ & $\begin{array}{l}\text { Basic flowability en- } \\
\text { ergy/mJ }\end{array}$ & Specific energy $/ \mathrm{mJ} \mathrm{g}^{-1}$ & $\begin{array}{l}\text { Avalanche Angle (de- } \\
\text { grees) }\end{array}$ & Rest Angle (degrees) \\
\hline$A$ & No flow & $870 \pm 30$ & $3.03 \pm 0.07$ & $42.9 \pm 0.3$ & $33.9 \pm 0.5$ \\
\hline B & No flow & $447.7 \pm 2.0$ & $3.65 \pm 0.02$ & $53.6 \pm 0.7$ & $40.2 \pm 0.4$ \\
\hline C & $15 \pm 1$ & $830 \pm 30$ & $2.97 \pm 0.11$ & $40.80 \pm 0.08$ & $32.30 \pm 0.08$ \\
\hline
\end{tabular}

Fig. 7: Spreadability metrics as a function of recoater speed and layer thickness for $\mathbf{a}, \mathbf{b}$, c Powder C and d Powder B
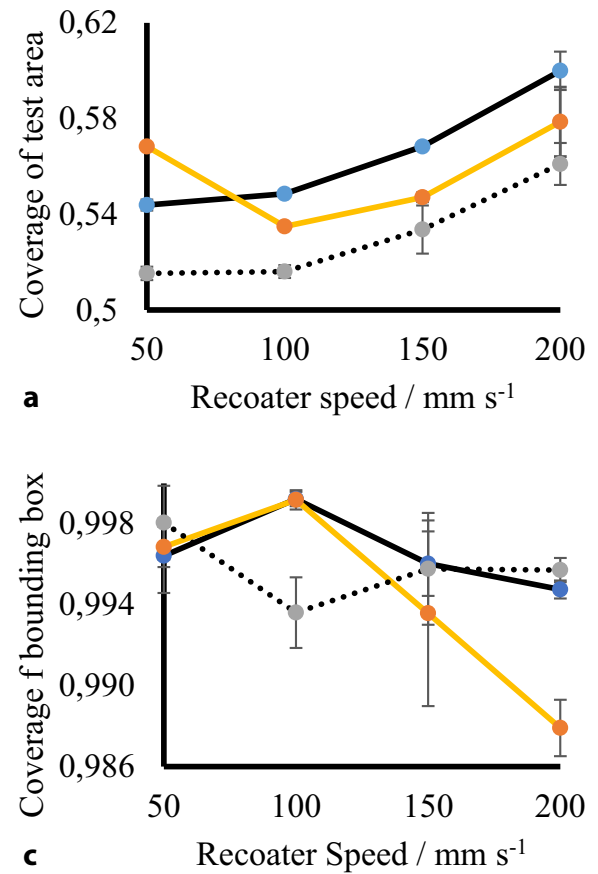
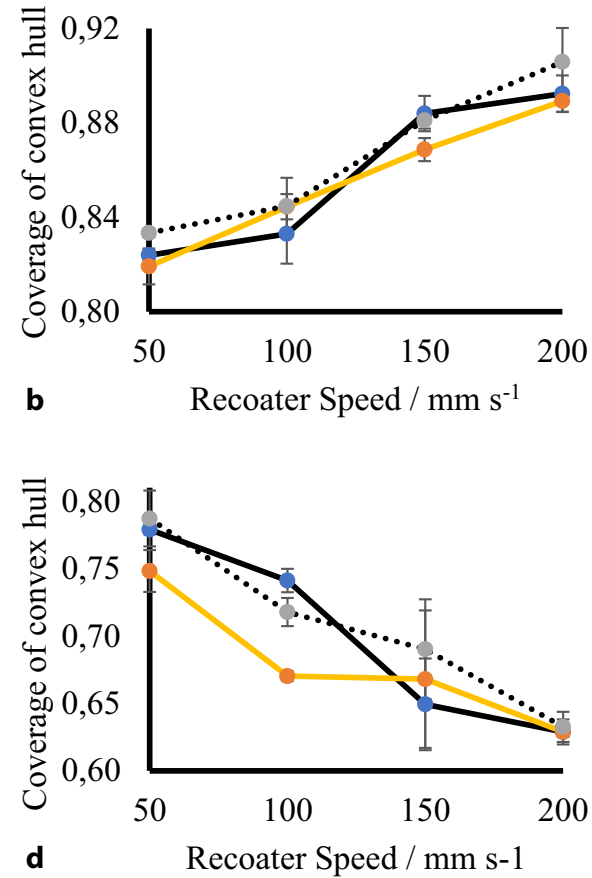


\section{Results}

The image analysis procedure is capable of identifying powder and assigning a convex hull and bounding box (Fig. 5).

Powder $C$ covers the greatest fraction of the area in which the powder could spread. Powder B covers the lowest area (Fig. 6). Similarly, Powder $C$ fills the greatest fraction of a bounding box and convex hull and Powder B the least. For Powder $\mathrm{C}$, the fraction of the available test area and the fraction of the bounding box filled by the powder increase with recoater speed for all layer thicknesses tested. There is a very small effect on the fraction of the bounding box that is covered by powder (Fig. 7a-c).

All three metrics decreased with increased recoater speed for powder B. Powder A had no strong relationship between recoater speed and the metrics. Powder $C$ covered less area at increased recoated speed, like Powder B. However, Powder B filled less of the convex hull and bounding box with increased recoater speed (e.g. Fig. 7d).

Both Powders A and B fail to flow through either a Hall or Carney flow funnel, while Powder $\mathrm{C}$ flows very readily (Table 2). Powder $C$ also exhibited the lowest "specific energy" during powder rheometry and Powder B the highest (Table 2). This is the most representative metric for the physical scenario of and agrees with the flowmeter results. In rotating particle analysis, that Powder $C$ exhibited the lowest avalanche and rest angles, while Powder B had the highest.

\section{Discussion}

If it is accepted that a "spreadable" powder spreads evenly across its entire width, maintains a constant thickness that is the nominal height of the blade, and that the layer cannot be higher than the height of the blade, one can say that a "spreadable" powder will fill the lowest area as but the highest fraction of the convex hull and the bounding box. These final two results are true for Powder $\mathrm{C}$, but it fills the greatest area. The high filling of the bounding box means that the length of the spread layer is even across the width of the layer and the high convex hull fill fraction implies that there are no protrusions in the spread layer. This is analogous to the use of circularity to characterise the shape of powder particles and other three-dimensional objects. The spread area can be thought of as analogous to the particle size distribution of a powder ensemble. Just as in characterisation of powders themselves, in which size and shape must be considered for a complete description, both the area of the layer and its form must be quantified to describe spreadability. This may be achieved with the proposed measurement and analysis procedure. Powder $\mathrm{C}$ was volatile and easily became airborne. It is conjectured that higher recoater speeds led to more powder becoming airborne and settling ahead of the spreading front, covering a larger area (Fig. 8).

Powder B was more cohesive and became airborne less than Powder C. Only the height and density of the layer will affect results. A faster recoater speed is more likely to cause

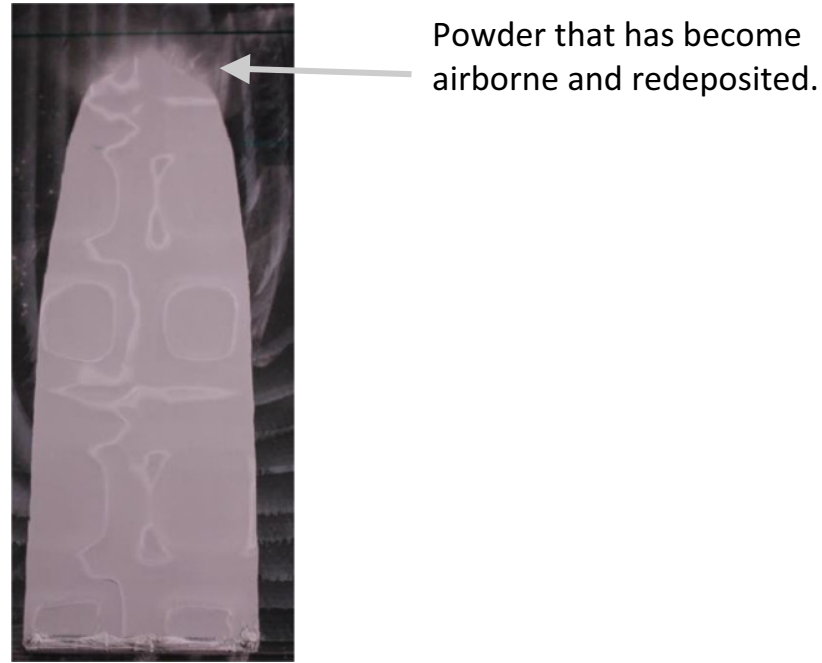

Fig. 8: $50 \mu \mathrm{m}$ layer spread at $50 \mathrm{~mm} \mathrm{~s}^{-1}$

defects in the spread layer, which leads to the powder filling a greater area.

Flowability and spreadability may be correlated as the same physical processes occur in both flow and spreading [9]. The rheometry results correlate with spreadability, since the specific energy of Powder $C$ is lowest, implying best flow. Powder $B$ has the highest specific energy, implying worst flow (Table 2 cf. Fig. 6). However, more tests are needed as the specific energies of Powders $A$ and $C$ match within standard deviation. Similarly, the rotating powder analysis showed that Powder $\mathrm{C}$ had the lowest avalanche angle and the lowest rest angle, implying best flow, and Powder B had the highest angles.

\section{Conclusions}

A technique to quantify the spreading behaviour of powders using an image analysis has been developed. Three powders were compared under various conditions that are relevant to metal additive manufacturing. It was found that the powder with the highest flowability gave the highest fraction of bounding box and convex hull filled, but not the smallest total area coverage. This was attributed to the powder becoming airborne and redepositing ahead of the spread layer.

\section{Future Work}

A wider range of powders and conditions should be tested to assess the suitability of the method. The investigation should also be repeated with a non-magnetic base plate to test the effect of magnetic fields on the behaviour of the powder. The technique can be developed further to include mass-based measurements, such as calculating the mass of powder included in a spread layer of fixed area, which is more representative of powder bed additive manufacturing. Further image analysis could be added, such as the 
analysis of dark regions to reveal porosity or unevenness [10].

Acknowledgements. The authors gratefully acknowledge Uddeholms AB for supplying powders and Simon Lindström and Lucas Brisemark for developing the image analysis procedure.

Funding. Open access funding provided by Royal Institute of Technology.

Open Access This article is licensed under a Creative Commons Attribution 4.0 International License, which permits use, sharing, adaptation, distribution and reproduction in any medium or format, as long as you give appropriate credit to the original author(s) and the source, provide a link to the Creative Commons licence, and indicate if changes were made. The images or other third party material in this article are included in the article's Creative Commons licence, unless indicated otherwise in a credit line to the material. If material is not included in the article's Creative Commons licence and your intended use is not permitted by statutory regulation or exceeds the permitted use, you will need to obtain permission directly from the copyright holder. To view a copy of this licence, visit http://creativecommons.org/licenses/by/4.0/.

\section{References}

1. Gao, W. et al.:The status, challenges, and future of additive manufacturing in engineering, Comput. Aided Des. 69 (2015), pp. 65-89

2. SS-EN ISO 13517:2013 Metallic powders-Determination of flow rate by means of a calibrated funnel (Gustavsson flowmeter), ISO, 2019

3. SS-EN ISO 4490:2018 Metallic powders-Determination of flow rate by means of a calibrated funnel (Hall flowmeter), ISO, 2018

4. ASTM B417-13 Standard Test Method for Apparent Density of NonFree-Flowing Metal Powders Using the Carney Funnel, ASTM International, 2013
5. ASTM B212-17 Standard Test Method for Apparent Density of FreeFlowing Metal Powders Using the Hall flowmeter Funnel, ASTM International, 2017

6. ISO 4324 Surface active agents-Powders and granules-Measurement of the angle of repose, ISO, 1977

7. ASTM B243-16a Standard Terminology of Powder Metallurgy, ASTM International, 2017

8. ASTM F3049-14 Standard Guide for Characterizing Properties of Metal Powders Used for Additive Manufacturing Processes, ASTM International, 2014

9. SS-EN ISO 52907:2020 Additive manufacturing-Feedstock materials-Methods to characterize metal powders, ISO, 2020

10. Ahmed, M.; Pasha, M.; Nan, W.; Ghadiri, M.: A simple method for assessing powder spreadabilit for additive manufacturing, Powder Technol. 367 (2020), pp. 671-679

11. Snow, Z.: Understanding Powder Spreadability in Powder Bed Fusion, Master's thesis, The Pennsylvania State University, 2018

12. Snow, Z.; Martukanitz, R.; Joshi, S.: On the development of powder spreadability metrics and feedstock requirements for powder bed fusion additive manufacturing, Addit. Manuf 28, (2019), pp. 78-86

13. A. Saharan, A.; Lasalle III, E. R.: Optical powder spreadability sensor and methods for powder-based additive manufacturing, US Patent 16/148302, 2019

14. van den Eynde, M.; Verbelen, L.; van Puyvelde, P.: Assessing polymer powder flow for the application of laser sintering, Powder Technol., 286 (2015), pp. 151-155

15. Schneider, C. A.; Rasband, W. S.; Eliceiri, K. W.: NIH Image to ImageJ: 25 years of image analysis", Nat. Methods, 9 (2012), pp. 671-675.

Publisher's Note. Springer Nature remains neutral with regard to jurisdictional claims in published maps and institutional affiliations. 